\title{
Geodynamic Features of the Northwestern Part of the Magellan Seamounts, Pacific Ocean
}

\author{
S. I. Petukhov'1, V. M. Anokhin'1, M. E. Mel'nikov² \& V. G. Vdovin ${ }^{3}$ \\ ${ }^{1}$ All-Russia Research Institute of the Geology and Mineral Resources of the World Ocean, St. Petersburg, Russia \\ ${ }^{2}$ State Scientific Centre, Federal State Unitary Geological Enterprise Yuzhmorgeologiya, Gelendzhik, Russia \\ ${ }^{3}$ Geologist, Calgary, AB, Canada \\ Correspondence: V. M. Anokhin, All-Russia Research Institute of the Geology and Mineral Resources of the \\ World Ocean, St. Petersburg, 190121, Russia. Tel: 7-921-796-9107. E-mail: vladanokhin@yandex.ru
}

Received: April 18, 2014

Accepted: August 16, 2014

Online Published: February 8, 2015

doi:10.5539/jgg.v7n1p35

URL: http://dx.doi.org/10.5539/jgg.v7n1p35

\begin{abstract}
A lineament analysis of the sea-floor relief in the north-western part of the Magellan Seamounts has been performed on the basis of the detailed bathymetric map of the area, which was created based on the results of multibeam echo sounding. According to the analysis, linear features of the relief were identified, the bearings of their strikes were measured and rose-charts of the lineaments in the study area were produced. Next, models of deep and subsurface deformation fields in the area were constructed emphasizing the blocks that were dominated by tensile or compressive stress. Interrelated movements of the blocks take place along the lines of sign changes of the stresses (along the block boundaries). The spatial and genetic relationships of the lineaments of the relief and the block boundaries were suggested by comparing the rose-diagrams of their directions. Both the linear system of landforms and the boundaries of deep and shallow blocks partially correspond to the four main systems of regmatic global network, which indicates a significant influence of the regmatic network on the structural plan of the area. Redistribution of stress values in the blocks appears to be associated with modern geological processes leading to formation of new features of the seafloor topography and partial destruction of guyots' old surfaces.
\end{abstract}

Keywords: block, compression, deformation, extension, guyot, relief, strain, stress model

\section{Introduction}

The Magellan Seamounts represent an arcuate chain of underwater volcanic edifices more than $1200 \mathrm{~km}$ long, which divides the East Mariana Basin into two basins: the northern one - Pigafetta Basin, and the southern one Saipan Basin. On the west, the chain is limited by the Mariana system of trenches and rises, on the east - west it is bounded by rises of the Big Caroline and Marshall Islands (Figure 1). In spite the fact that the Magellan Seamounts are the most prospective region for Co-rich ferromanganese ore mineralization of the crust type, its genesis did not attract serious attention of Russian and foreign researchers for a long time. This had created problems for geologists engaged in the questions of the mineralization because comprehension of the structure of mineral deposits demands clear understanding of its tectonic position. However, with the accumulation of geophysical data, emergence of altimetric ocean maps, on the verge of the centuries there appeared numerous works explaining the nature of the Magellan Seamounts from different points of view (Brusilovsky, Gorodnitzky, \& Sokolov, 1992; Sedov et al., 2005; Utkin, Khanchuk, Mikhailik, \& Khershberg, 2004; Gavrilov, 2005; Koppers, Staudigel, Wijlbrans, \& Pringle, 1998).

The followers of the plate tectonics concept believe that the seamounts came into existence as volcanic edifices in the southern part of the Pacific Ocean in the vicinity of a hot spot zone SOPITA and later migrated toward their present-day position within a drifting plate (Sedov et al., 2005; Koppers et al., 1998). Other researchers hold the opinion that the Magellan Seamounts represent a wide zone of a transform fault (in this case, the Ogasavara fault) which separates plate fragments of mid- Jurassic (the Pigaffeta Basin) and late Jurassic (the Saipan Basin) ages (Brusilovsky et al., 1992).

There are some other hypotheses regarding the Magellan Seamounts genesis not related to the mobilism mechanics. According to V.P. Utkin with co-authors (2004) the main role in the formation of guyots of the 
Magellan Seamounts was played by shear dislocations of different orders which were revealed in plicated and disjunctive forms (Utkin et al., 2004). Also there were other interpretations that the Magellan Seamounts are a part of a central type ring structure and possible formation mechanisms of such structures were related with mantle diapirism (Gavrilov, 2005).

For 25 years research vessels of the Marine Geological Survey of Russia have conducted geological and geophysical investigations of the Magellan Seamounts which have been oriented on the determination of the economic perspective of their ferromanganese mineralization. During this period, a seismo-acoustic profiling and hydromagnetometric survey were carried out in the region. From 2000 to 2010, a bathymetric survey of all large guyots of the Magellan Seamounts chain (its western and eastern parts) was performed by the R/V Gelendzhik of the Yuzhmorgeologiya State Scientific Centre using a multibeam echo sounder SIMRAD EM $12 \mathrm{~S}-120$. Within the western part of the chain, which will be discussed in this study, the entire area covered by the bathymetric survey made up more than $60,000 \mathrm{sq}$. $\mathrm{km}$. The conducted works allowed collecting a vast amount of data and substantiating our ideas regarding the geological structure and nature of the reviewed formation.

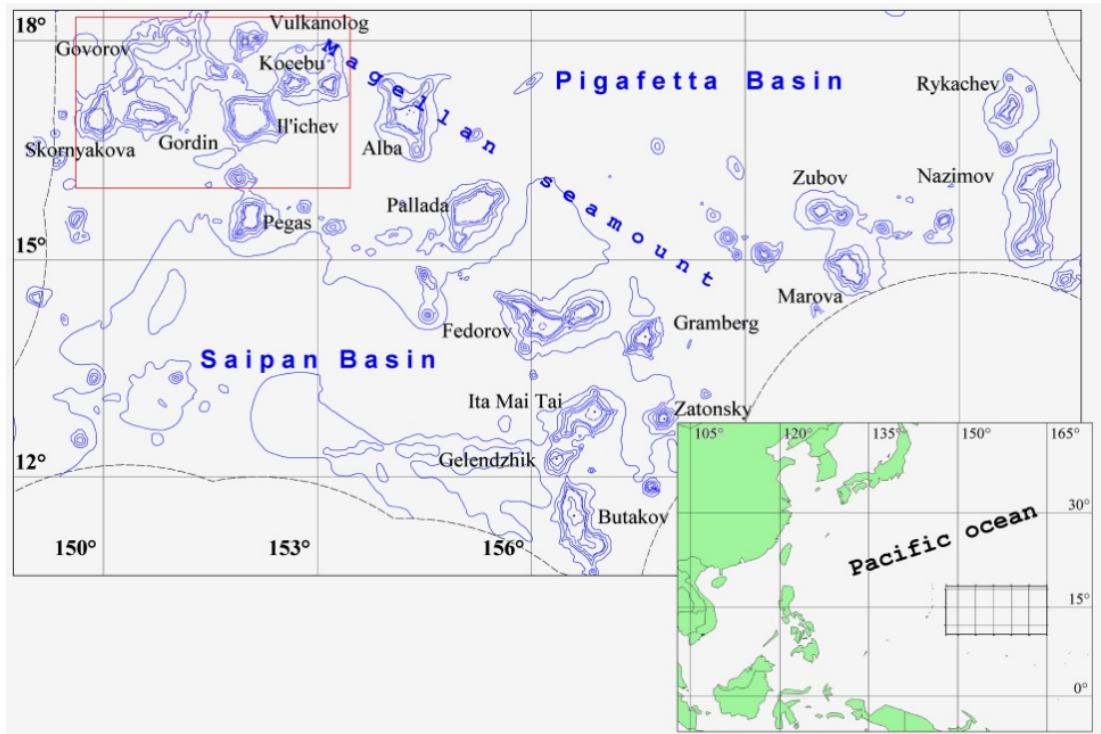

Figure 1. Schematic location of guyots of the Magellan Seamounts

Note. The inset shows the position of the study area in the Pacific Ocean.

\section{Region Settings}

\subsection{Bottom Topography}

In this paper the northwestern part of the Magellan Seamounts' west link is discussed. The most part of the study area is represented by the volcanotectonic Govorov-Kocebu massif which consists of five seamounts: Govorov, Skornyakova, Gordin, Kocebu, and Il'ichev. The massif base is contoured by the 5,500 m isobath; Govorov, Kocebu, and Il'ichev guyots are contoured by the 4,700 $\mathrm{m}$ isobath; Skornyakova and Gordin guyots - by the $3,700 \mathrm{~m}$ isobath. The area of the massif is more than $43,500 \mathrm{sq} . \mathrm{km}$. The Skornyakova and Gordin guyots are characterized by relatively small dimensions at their base: $91 \times 64 \mathrm{~km}$ and $88 \times 55 \mathrm{~km}$ respectively. The Il'ichev and Kocebu guyots are represented by a larger area at their base: 90 x $88 \mathrm{~km}$, and 115 x $95 \mathrm{~km}$ respectively. The Kocebu Guyot is a two-summit guyot. Summit plateaus of all these guyots are located at the level of about 1.5 $\mathrm{km}$, only a plateau of the Kocebu eastern edifice is at the level of $1.3 \mathrm{~km}$. The Govorov Guyot has a very large area $(190 \times 180 \mathrm{~km})$ and an irregular shape complicated by a number of satellite formations. The summit plateau of the main guyot is located deeper than plateaus of the rest guyots, at $2 \mathrm{~km}$.

The Skornyakova and Gordin guyots are separated from the southwestern satellite of the Govorov Guyot by gently sloping saddles and they are separated from each other by a vast, valley-like depression at the depths of $3.6-3.9 \mathrm{~km}$. The northern slope of the Gordin Guyot and the southwestern slope of the Govorov Guyot are divided by a deep narrow hollow with width about $15 \mathrm{~km}$ and depth up to $0.7 \mathrm{~km}$. There is a vast gentle ridge between the southeastern satellites of the Govorov and Il'ichev guyots on the depth of $4.7 \mathrm{~km}$. The Kocebu Guyot, on its turn, is connected with the northeastern spur of the Il'ichev Guyot by a narrow arch on the level of 
$4.7 \mathrm{~km}$. The length of the arch is about $10 \mathrm{~km}$ and the width is $6 \mathrm{~km}$. A small guyot named Vulkanolog $(65 \times 52$ $\mathrm{km}$, depth of the summit plateau is $1.3 \mathrm{~km}$ ) and located on the northeastern border of the study area, is not included into the reviewed massif for it is contoured by the 5,200 m isobath. Such a depth is typical for the Pigafetta Basin subsurfaces in the area of junction with structures of the lower slopes of guyots in this region. However, the Vulkanolog Guyot could also be genetically related to other guyots of the massif, not being its part at the same time.

Located to the south from the Il'ichev Guyot, the Pegas Guyot is relatively isolated one; its area at the base makes up $82 \times 75 \mathrm{~km}$ and its plateau is at the $1.5 \mathrm{~km}$ level. In between these guyots there is a small guyot-satellite with a diameter of its base less than $35 \mathrm{~km}$ and its plateau is at the same depth.

All the guyots, in general, have similar features. Only the largest guyot (Govorov) and the smallest one (Vulkanolog) fall out of the common trend.

\subsection{Geologic Setting}

Seamounts of the western link, as the rest guyots of the Magellan Seamounts, consist of Lower Cretaceous volcanic rocks which are represented by tholeiite-alkali-basalt association of the Hawaiian type (Volokhin, Mel'nikov, \& Shkol'nik, 1995). Two complexes are identified here. The lower one is represented by plitotholeiites, and the upper one consists of subalkali and alkali basaltoids within which picrites, alkali olivine basalts and trachybasalts are identified.

Depositional cap may reach the thickness of one $\mathrm{km}$ and consists of complexes of sedimentary and volcanogenic-sedimentary rocks of Aptian-Turonian, Campanian-Maastrchtian, Late Paleocene-Eocene, and Miocene (Volokhin et al., 1995; Mel'nikov, 2005; Pletnev, Mel'nikov, \& Punina, 2010). Nonconsolidated Pliocene-Quaternary sediments crown this section. Composition of rocks of all different complexes is similar and includes reefal and planktonic limestones, edaphogenic breccia, and fine detrital rocks. Shallow water deposits are not present in the Miocene complex. Every complex contains volcanogenic - clastic and volcanogenic-sedimentary rocks of narrow age intervals. Their presence indicates regular display of volcano-tectonic activation in the region during the Late Cretaceous - Miocene time.

\section{Methods}

Vast data from the multibeam echo sounding carried out in the subject region during last 10 years, at a scale of 1:200,000, allowed us to produce a detailed bathymetric map of the region, which served as a basis for the lineament analysis of the bottom topography.

In this work, a term "lineament" is understood by the authors as a structure of the crust expressed by linear elements of land or sea bottom, by linear geological features, by linear anomalies of physical fields of the Earth; these structures have direct or indirect relationship with faulted zones and zones of the anomalous permeability in the crust (Anokhin, 2006). The lineament analysis was carried out based on this definition.

During the analysis, linear forms of relief -crests, hollows, and ledges - were outlined, and their strike directions were measured. After this, a rose-diagram of the lineament directions was built by means of EXEL application, then, using the software program Maple, a model of the deformation field of the Magellan Seamounts region was created.

Construction of deformation models has been carried out at the Federal State Unitary Enterprise "VNII Okeangeologiya" for more than 10 years (S. Petukhov, Aleksandrov, \& Andreev, 2010). At first, these models were applied for search of fields of hydrothermal activation in the areas of the Mid-Atlantic Ridge. By doing this, the relationship between active hydrothermal fields and tense zones of crust (compression, extension or relief zones) has been revealed. Strained condition is characterized by values of normal ( $\sigma$ norm) and tangent ( $\tau$ tang) strain, thus, for compression $-\tau$ tang $<0$; for extension $-\tau$ tang $>0$, and for relief $-\tau$ tang $=0$ (Aleksandrov, Anikeeva, Andreev, \& S. Petukhov, 2009). The same method has been applied in this study. The seabottom relief served as a primary datum for creating a deformation model. Two versions were used for building the deformation model. In the first version, on a preliminary stage, a chart of the blocky bottom relief was built by the method of geodynamic division into regions (Figure 2). Revealing of the blocky structure of seabottom relief using the method of geodynamic division is based on idea of different intensity of vertical motions of blocks along a system of faults of different ages and depths of their formation. It is believed that any horizontal motions of blocks are reflected on their vertical motions (I. Petukhov \& Batugina, 1999). Along such faults the present-day movements occur. Geometrization of the tectonic relief of the seabottom allows for understanding its deep structure, and the process of its formation in geohistorical aspect. 


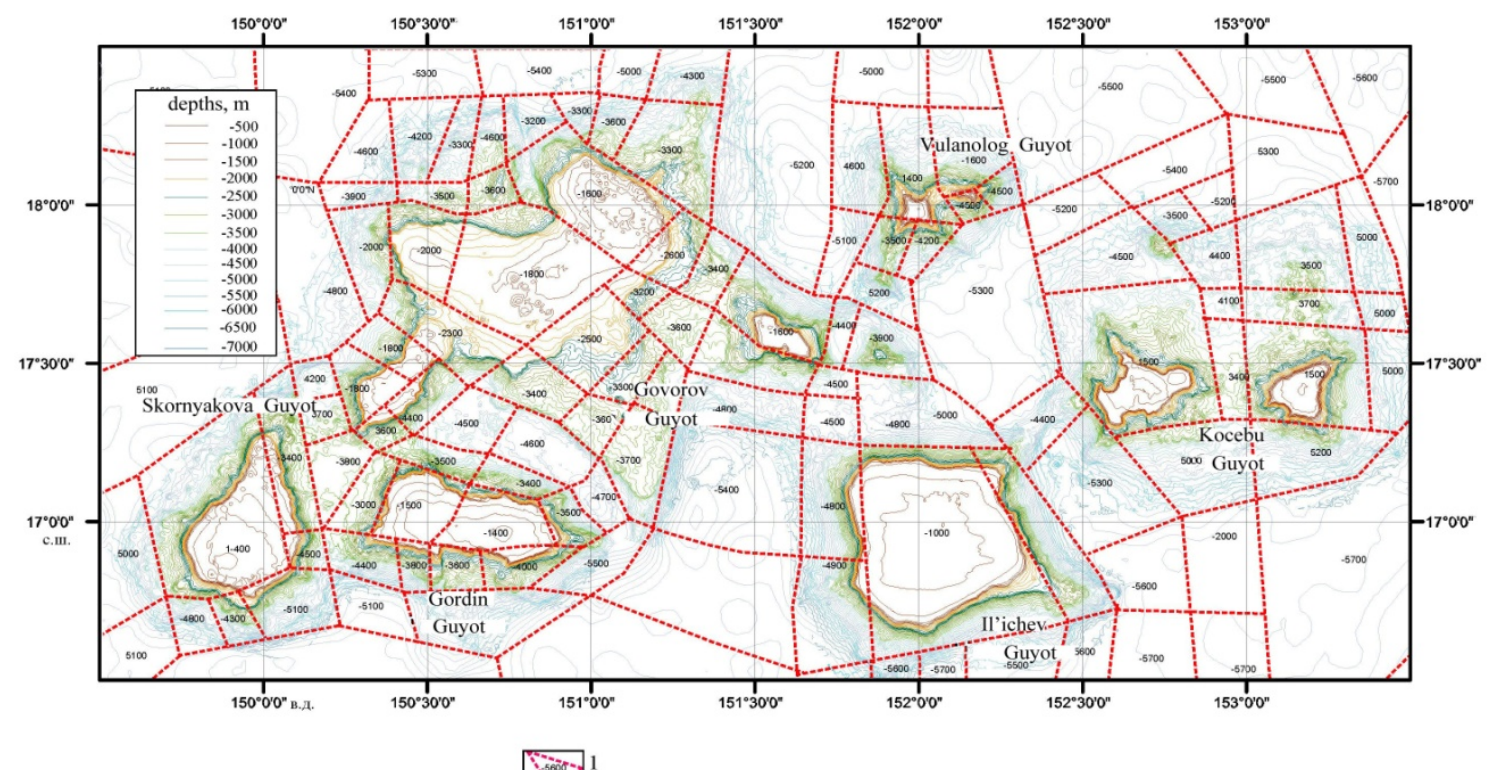

Figure 2. Scheme of block structure of the region as a basis for the construction of the deformation model of the crust (for the first version)

Note. (1) - block boundary and its depth mark, $\mathrm{m}$.

The main element in a block structure is a block marked out by a unified complex of indications. A block, in this case, is a section of crust with a relatively even hypsometric field of height points (I. Petukhov \& Batugina, 1999). Identification of a blocky structure is carried out in the following sequence:

- On a map, the base heights are picked out;

- Each chosen height is marked on the map with a prearranged sign, which shows what a height level belongs a given section.

At any particular section, 0.1(Hmax - Hmin) can be taken as a minimum difference, where Hmax - the absolute maximum elevation of the relief, and Hmin - the absolute minimum elevation of the relief. Indicative signs of faults limiting blocks are represented by deep water trenches, segments of linearly elongated isobaths, characterizing ledges; chains of local submergences; linear segments of islands, piedmonts; chains of seamounts, bottoms of depressions, sections of oceanic plateaus; and featured configurations of isobaths (I. Petukhov \& Batugina, 1999).

The received block model of the seafloor relief was then approximated by a two-layer structure; the thickness of the upper, elastic - plastic layer was considered to be a half of the thickness of the lower, plastic deformation layer. Such an approach is believed to be true due to lamellar structure of the oceanic crust. With this, it has been assumed (Aleksandrov et al., 2009) that under the influence of the weight of the upper layer, plastic deformation of the lower layer occurs; the magnitude of this deformation depends on the height marks of the blocks. Through this process it is possible to register the changes in the nature of the oceanic floor topography (Figure 3).

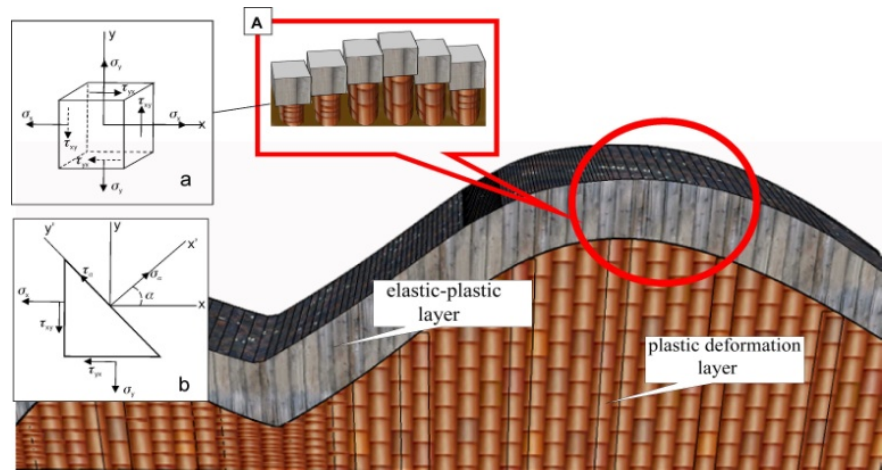

Figure 3. Model of bilayer bottom structure 
By having these physical properties (elastic modulus, the Poisson ratio, density), the assumed model is an equivalent of the oceanic crust consisted of tholeiite basalts and with thickness around $5 \mathrm{~km}$, which is typical for numerous ocean areas (Aleksandrov et al., 2009).

For calculating deformation fields of guyots the method of finite elements (MFE) was used. This allowed the approximation of a complex relief with constantly changing surface by using a set of large number of segments. For each segment, a system of linear algebraic equations was solved. By having defined the values of potential energy for each finite element it is possible to describe normal and tangent strains existing in them (Aleksandrov et al., 2009).

Based on results of modeling there were revealed regions being in compression conditions $(\tau \operatorname{tang}<0)$, extension ( $\tau$ tang $>0)$, and also relatively unloaded areas with "zero", as we believed, values of tangent strain $(\tau \operatorname{tang}=0)$. Then, a chart of the estimated strain conditions of the block massif is built (Figure 4) and the " 0 "isoline is highlighted (a relief zone with $\tau$ tang $=0$ ).

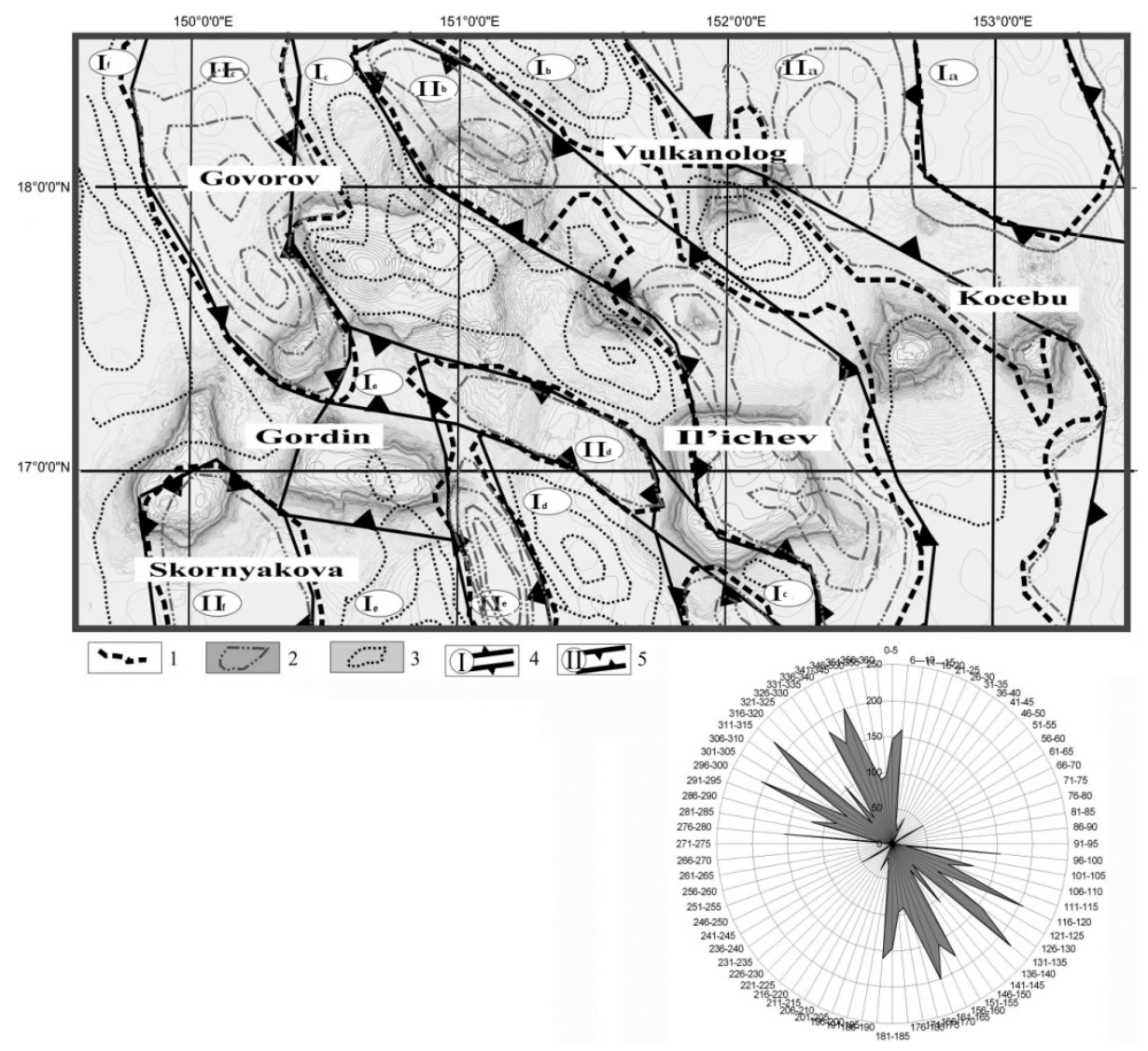

Figure 4. Deformation model for the crust for the deep block structure of the ocean floor (the first version)

Note. (1) - isolines characterizing discharge zone, (2) - isolines characterizing compression zone, (3) - isolines characterizing extension zone, (4) - extension zone, (5) - compression zone. The rose-diagram shows directions of the border zones between extension and compression; on the dial - azimuths, deg., radial scale - length, km.

In the second version, a calculated deformation model was built by using bathymetric data of the seabottom topography. The relief built by using the application Maple is simplified compared with the bathymetric, however it fully imitates all main morphostructures of the study area (Figure 5).

The bottom relief of the study area has also been, as in the first version, approximated with a two-layer structure, where thickness of the upper, elastic-plastic layer was equal to $1 / 5$ thickness of the lower one (Figure 3). Working directly with the bathymetric base allows to more correctly modeling the main features of the structure of the present-day seabottom topography in the study region. 


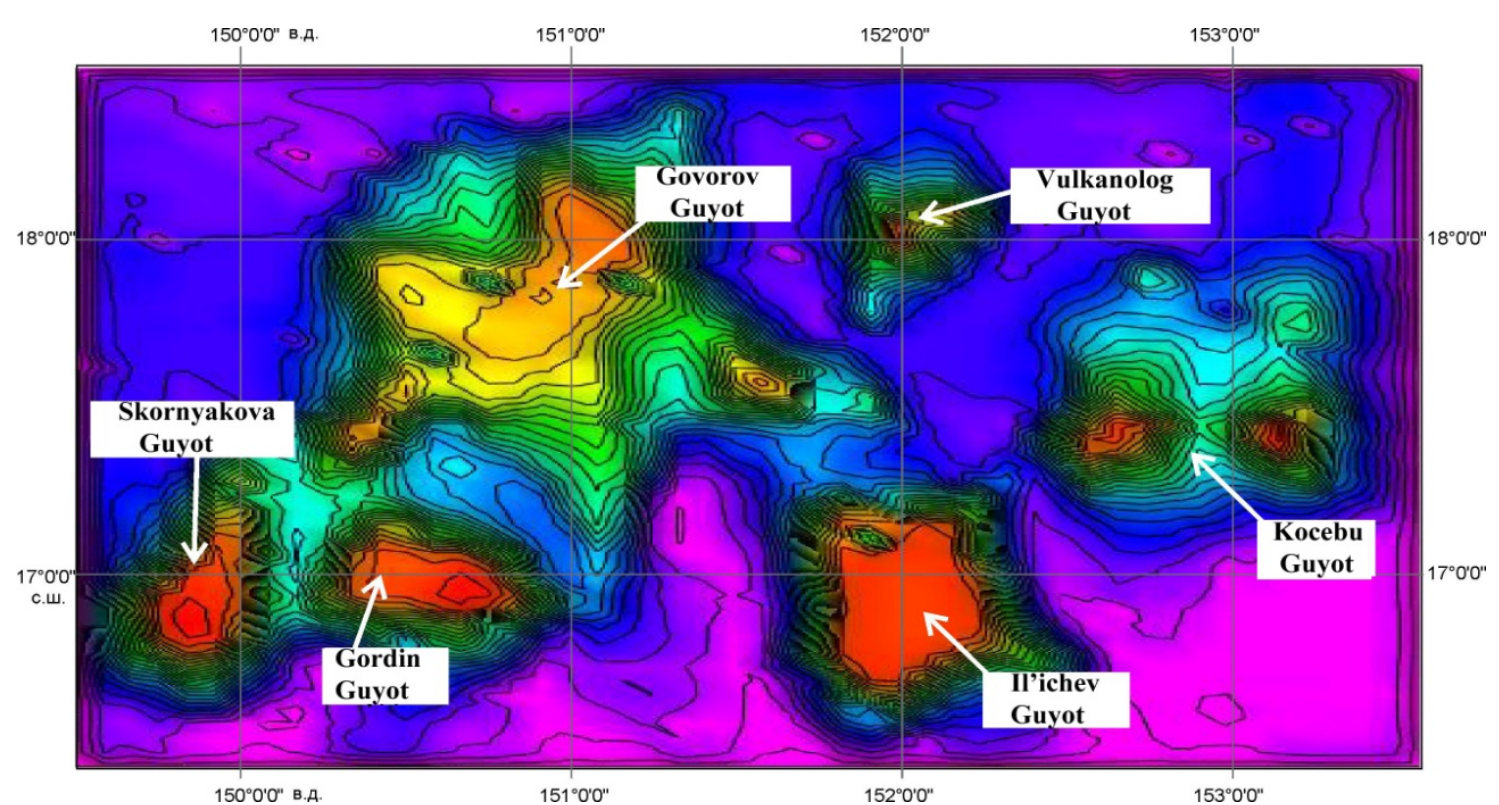

Figure 5. Relief model - the basis for the construction of the surface deformation model (for the second version)

\section{Results}

The outlined linear features of the relief of the investigated region are represented on Figure 6. Their overall directions are shown on a rose-diagram (Figure 7). The lineament directions of the area are characterized by presence of several main systems: sub-meridian $\left(0-5^{\circ}\right)$, sub- latitude $\left(86-90^{\circ}\right)$, diagonal NE $\left(46-50^{\circ}\right)$, and diagonal SE $\left(131-140^{\circ}\right)$, which in general corresponds with the systems of global lineament-disjunctive network (Anokhin, 2006). However, the region is specified by "divaricating" of rays of main systems, with that, additional rays, $101-110^{\circ}, 146-155^{\circ}$, appear, along with less significant, $11-15^{\circ}, 31-35^{\circ}$, and $61-65^{\circ}$. Similar occurrences of "divarication" of rays of main systems of directions of the relief linear elements have been noticed at the NE slope of the Govorov Guyot (Anokhin \& Mel'nikov, 2010).

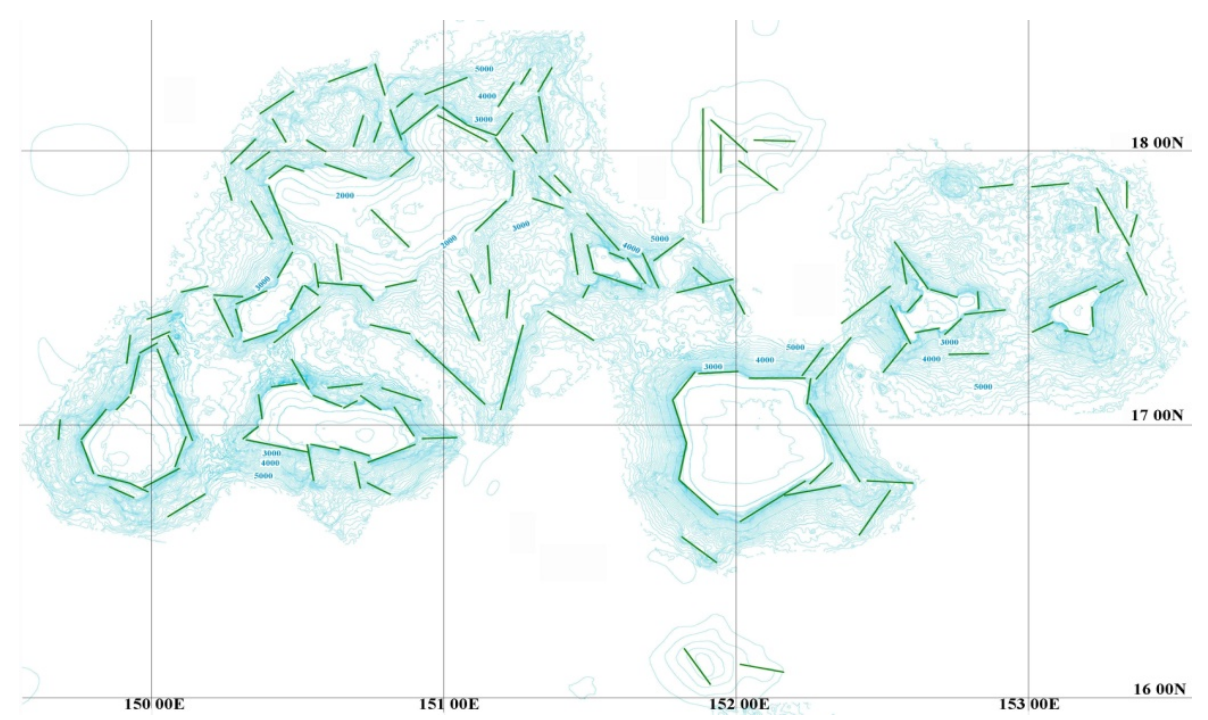

Figure 6. Bathymetric map of the northwestern part of the Magellan Seamounts with lineaments

Note. Light grey curves - isobaths, c.i. $=100 \mathrm{~m}$; dark grey segments - marked lineaments.

In the first version (Figure 7), a scheme of preliminary outlined the block structure of the study area served as the base for constructing the deformation model (Figure 2). In the second version (Figure 8) the modeling of distribution of stress was carried out directly on the basis of the relief built with the Maple application (Figure 5). 
In both cases, areas under compression, extension, and relatively relieved, with " 0 " tangent strain, were revealed. Based on the results of modeling, maps of the western chain of the Magellan Seamounts were built; on these maps, zones with strained conditions (compression or extension) were shown, and also the zone of relief (discharge) - "0" line - was outlined (Figures 4, 8) (Aleksandrov, et al., 2009).

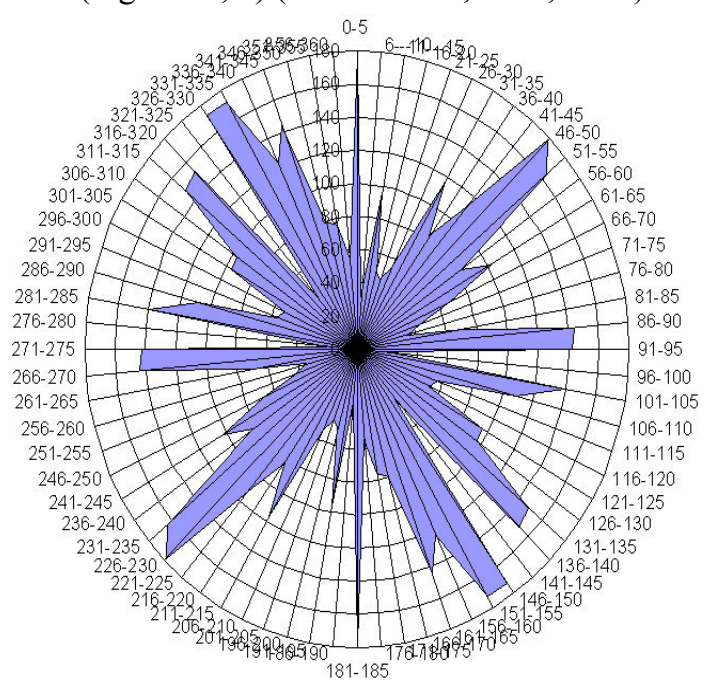

Figure 7. Rose-diagram of lineament directions for the northwestern part of the Magellan Seamounts

Note. On the dial - azimuths, deg., on the radial scale - the total length of lineaments, $\mathrm{km}$.

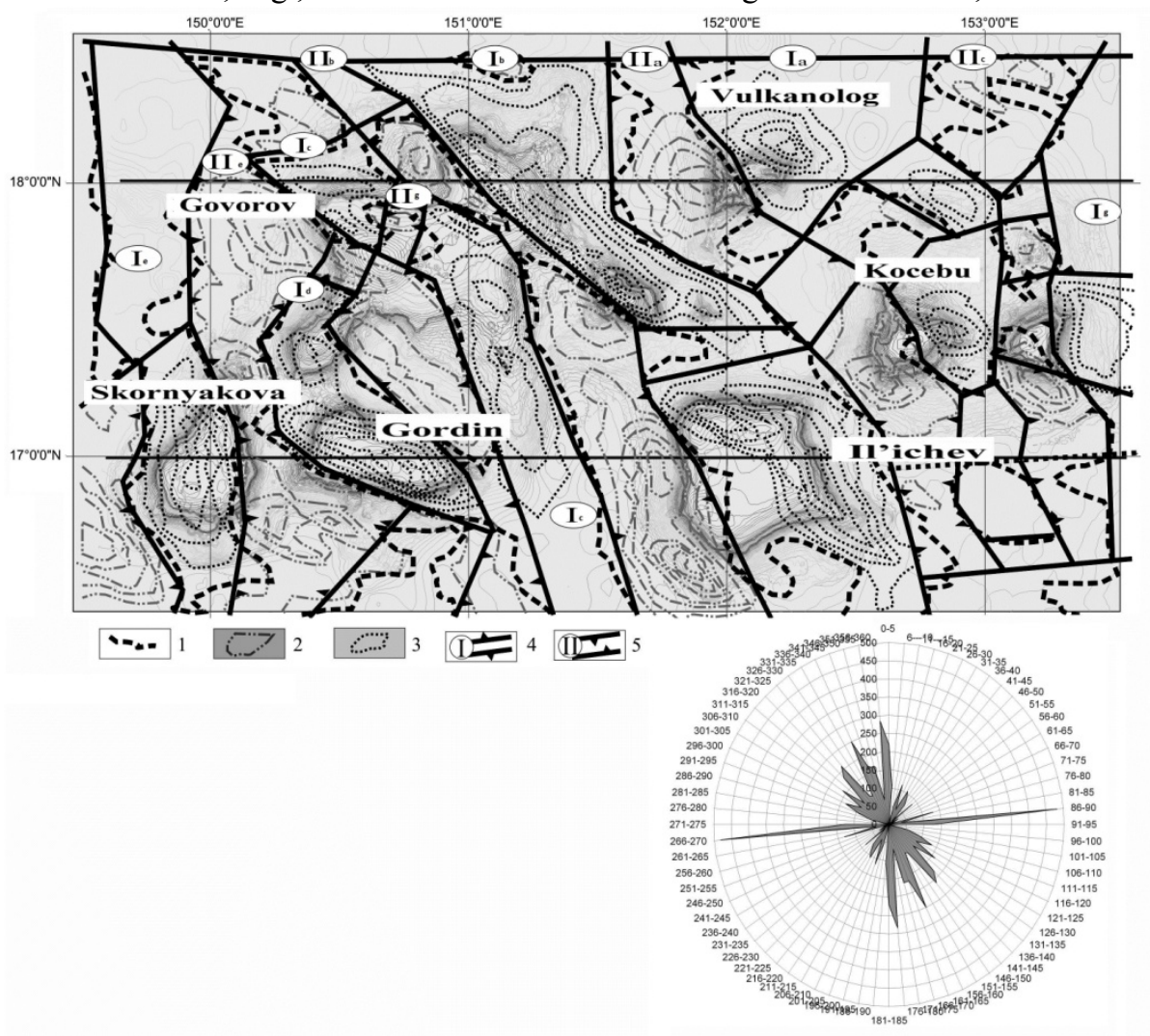

Figure 8. Crust deformation model for the surface relief model (the second version)

Note. (1) - isolines characterizing discharge zone, (2) - isolines characterizing compression zone, (3) - isolines characterizing extension zone, (4) - extension zone, (5) - compression zone. Roman numerals on the diagram mark the extension zone (I) and the compression zone (II). On the rose-diagram shown the directions of the border zones between extension and compression; on the dial - azimuths, deg., on the radial scale - length, km. 
As it was shown earlier, the base for creating the deformation model in the first version (Figure 4) was a map of block structure of the oceanic bottom surface (Figure 2) built using the method of geodynamic regioning during the preliminary stage. This shows more definitively the block structure of the foundation (Brusilovsky et al., 1992; I. Petukhov \& Batugina, 1999).

Vulkanolog - Kocebu Zone. The Vulkanolog and Kocebu guyots are located within a single elongated zone of extension strains $(\mathrm{Ib})$ and their foundations represent mono-block structures.

Govorov - Il'ichev Zone. The Govorov Guyot has a block structure. Based on the character of the deformation strains, the guyot could be divided into three parts. The eastern and western parts are characterized by compression strain (IIb ) and (IIc) and its central part is associated with extension strain (Ic). The central part of the Il'ichev guyot is located in the area of compression (IIb), and its western part is in the area of extension strains (Ic), which indicates a blocky nature of its foundation.

Gordin Zone. The Gordin Guyot is situated in a zone of extension strain (Ie) and its foundation is represented by a single block.

Skornyakova Zone. The northern part of the Skornyakova Guyot is found to be in condition of extension strain (If) and southern - in condition of compression (IIf), which notes its blocky structure.

As shown on the rose diagram (Figure 7), the boundaries of divided blocks in the given model have mainly NW-SE directions of $116-120^{\circ}, 131-135^{\circ}$, and $151-165^{\circ}$. Perhaps, this is associated with predominance of the horizontal strain of meridian direction in this region (Utkin et al., 2004).

Different from the schematic map shown on Figure 4 and describing the distribution of stress in the foundation, on Fig. 8 there is a model of stress distribution calculated directly from the relief of the study area and reflecting the stress distribution in the upper part of the section which could be compared, at the first approximation, with a sedimentary sequence.

When analyzing the schematic map of the second version of the deformation model of the Magellan Seamounts region (Figure 8) it could be noted the interchange of submeridian zones of extension and compression within the study area. On the schematic map they are marked by Roman numerals.

Vulkanolog - Kocebu Zone. While the central part of the Kocebu guyot foundation lies in the extension conditions (Ia), its eastern (IIb) and western (IIa) parts are in conditions of compression. The eastern slopes of both edifices of the Kocebu guyot are stress relief areas, and their summits lie in the compression strain areas. The eastern part of the Vulkanolog guyot is located in the conditions of extension strain (Ia), and its western part is in conditions of compression (IIa).

Govorov - Il'ichev Zone. The Govorov Guyot has a blocky structure complicated by numerous spurs and satellite edifices. Depending on the character of the deformation stress, the guyot may be divided into several parts. The eastern part is characterized by extension strain (Ib), the Il'ichev guyot lies in the same zone of extension. The central part of the guyot is located as in the zone of compression (IIb) and in the zone of extension (Ic); the southern spur of the guyot lies in this sector as well.

Govorov - Gordin Zone. The southwestern satellite of the Govorov Guyot is separated from the central part by the zone of compression (IIe) and located in the zone of extension (Id). The Gordin Guyot lies in the same zone (Id). The Gordin Guyot, being in the conditions of extension strain (Ie), is separated from the Skornyakova Guyot by the zone of compression (IIe).

The pattern view of the deformation field of the study area guyots of the Magellan Seamounts by the character of stress sign change has an appearance of "an accordion": fields of extension strains are changed by fields with compression strains, which in turn yield to zones with extension strains. This phenomenon is perhaps related to the fact that the development of the region, as some researchers (Utkin et al., 2004) believe, occurred in conditions of meridian compression of oceanic crust. And with this, the formation of guyots is a compensation of tectonic strains of oceanic crust.

When analyzing rose diagrams of the directions of the block boundaries shown on the model (Figure 8), it may be noted the primary correspondence of these boundaries to the following main systems of directions: submeridional $\left(170-185^{\circ}\right)$, sublatitude $\left(86-90^{\circ}\right)$, diagonal (SE $\left.126-130^{\circ}, 141-145^{\circ}, 156-160^{\circ}\right)$. This rose diagram has similar features as with the rose diagram of directions of deep boundaries of the blocks (Figure $4-\mathrm{a}$ number of expressed southeastern systems) and as with the rose diagram of directions of linear structures of the relief (Figure 7 - presence of sublatitude and submeridional systems). A conclusion can be drawn from this about complex influence upon block configurations and related with them linear bottom topography as by endogenic 
stresses and so by global stresses (Anokhin, 2006).

\section{Discussion}

Any geological subject passes in its development stages of genesis, maturation and metamorphosis (up to complete destruction). At present-day time the guyots of the Magellan Seamounts are at the stage of alteration with elements of destruction which has begun, probably, after the formation of their summit surfaces. Traditionally, it has been considered that alteration of guyots happens exclusively under influence of exogenic factors. Our investigations reveal that an important role in the metamorphosis of guyots is also played by the tectonic factor. Processes related to actions of present-day stresses cause partial destruction of the earlier formed surfaces and, by this, shape new features of the relief.

The block structure conception of a guyot does not, in the whole, controvert the published data about the configuration of the anomalous magnetic field within the area of the Magellan Seamounts (Brusilovsky et al., 1992; Rashidov, Dolgal, \& Novikova, 2009; T. Lee, S. Lee, J. Moon, \& J. Lee, 2003). It has been already noted a consistent association of high- amplitude magnetic anomalies with morphostructural elements of a guyot relief such as slopes, spurs, etc. (Volokhin et al., 1995; Mel'nikov, 2005).

Similarity of the directions of the main systems of the linear relief and the direction of the block boundaries implies the spatial and probably genetic relationship with each other. The linear relief is partially controlled by possible faulted zones separating blocks from each other. The linear topography and the region fractures have a common genesis as a reaction on joint impact of horizontal and vertical stresses existing in the region. Analyzing the rose diagrams of directions of all linear objects (Figures 7, 4, 8), it should be noted the presence of developed systems corresponding to the directions of the global disjunctive network (planetary fracturing) - submeridional, sublatitudinal and, to a certain extent, two diagonal directions. This fact implies the significant influence of the global scale (most likely rotational) forces on the relief- and fault-forming directions within the NW sector of the Magellan Seamounts (Anokhin, 2006).

In the study area of the Magellan Seamounts (Figure 8) guyots could be divided in two groups depending on their structural complexity. The Vulkanolog, Kocebu, and Govorov guyots, having a block pattern, belong to the first group; the Il'ichev, Gordin, Skornyakova guyots, having rather a simple structure (represented by a single block), belong to the second group. One part of blocks, sharing the structure of the first group guyots, experiences the compression strain, while another part of the same guyots are in conditions of extension strain; this is typical for the eastern parts of the guyots. Faults shown on Figure 8 are drawn along the areas located within the zones with " 0 value of tangent strain and mark the weakened sectors of guyots.

With comparison of two versions of deformation models for the Magellan Seamounts region (Figures 4, 8) the following conclusions could be made.

Once being homogeneous, the deformation zone of extension strain, where the Vulkanolog and Kocebu guyots are located, has been divided in several areas with compression and extension strains (zones Ia, IIa, and IIb, Figure 8) which indicates a block characteristics of the guyots and also the destruction processes intensively going on these guyots.

Rearrangement of stresses on the Govorov Guyot also indicates its destruction along the weakened zones (differential velocities of its submerging). Thus, it could be noted on the schematic map (Figure 4) showing stress conditions in the foundation, that the deformation field of the Govorov Guyot consists of three areas (Figure 4, zones Ic, IIb, and IIc); however, on the deformation model of the crust for subsurface relief model (the second version) which describes the deformation field of the upper horizons, the same field is already divided into 7 zones with different types of strain (Figure 8).

On the deep deformation model (the first version) the Il'ichev Guyot almost entirely lies within the zone of compression strain, as does the eastern part of the Govorov Guyot (Figure 4, zone IIb). At the same time, on the subsurface deformation model, the Il'ichev Guyot and the eastern part of the Govorov Guyot lie already within the extension conditions of strain (Figure 8, zone Ib). Such a change of stress types indicates the redistribution of the strain related to the destruction of the guyots.

The Gordin Guyot as in the deep deformation field (Figure 4) and in the subsurface deformation field (Figure 8) is represented by a monostructure which indicates an insignificant activation of destructive processes of the guyot at the modern stage of its development. 


\section{Conclusions}

1) The north-western section of the Magellan Seamounts, according to the character of the deformation strain field, has a blocky structure; comprised the guyots blocks are in the stressed conditions which are characterized by extension or compression strain. Block movements occur along the line of the change of the strain sign (the zone of relief).

2) The strain field of a single block could be a simple (including one strain zone) and complex (including interchange of several strain zones).

3) Similarity of directions of the main linear relief systems and the block boundaries indicates spatial relationship between them. Linear relief is often controlled by possible faulted zones, which separates blocks from each other. It may be suggested that the linear topography and the disjunctive zones of the region have significantly common genesis.

4) Systems of directions of the relief linear forms, deep and subsurface blocks boundaries partially correspond to four main systems of the globe disjunctive network (planetary fracturing) which indicates significant influence of the latter on the region structural plan.

5) Re-distribution of strain values is connected to the modern geologic processes leading to formation of new sea bottom relief features and partial destruction of guyots' old surfaces.

\section{References}

Aleksandrov, P. A., Anikeeva, L. I., Andreev, S. I., \& Petukhov, S. I. (2009). Talassochemistry of the World Ocean orogenes. St. Petersburg: Federal State Unitary Enterprise "VNIIOkeangeologia" [in Russian].

Anokhin, V. M. (2006). Global disjunctive network of the Earth: Structure, origin, and geological significance. St. Petersburg: Nedra [in Russian].

Anokhin, V. M., \& Mel'nikov, M. E. (2010). Structural features of the northeastern slope of Govorov Guyot, Magellan Seamounts, Pacific Ocean. Russian Journal of Pacific Geology, 4(4), $304-313$. http://dx.doi.org/10.1134/S1819714010040032

Brusilovsky, Y. V., Gorodnitzky, A. M., \& Sokolov, V. A. (1992). Volcanotectonic evolution of the Magellan Seamounts in the light of their geomagnetic investigation. Geotektonika, 5, 96-106.

Gavrilov, A. A. (2005). Ring morphostructures of the Pacific Ocean floor. In Regularities of the structures and evolution of exospheres: Proceedings of VII International Interdisciplinary Scientific Symposium and International Geoscience Prog. (pp. 73-78). Vladivostok, Russia.

Koppers, A. A. P., Staudigel, H., Wijlbrans, J. R., \& Pringle, M. S. (1998). The Magellan seamount trail: implication for Cretaceous hotspot volcanism and absolute Pacific plate motion. Earth and Planetary Science Letters, 16, 53-68. http://dx.doi.org/10.1016/S0012-821X(98)00175-7

Lee, T. G., Lee, S. M., Moon, J. W., \& Lee, K. (2003). Paleomagnetic investigation of seamounts in the vicinity of Ogasawara Fracture Zone northwest of the Marshall Islands, western Pacific. Earth Planets Space, 55, 355-360. http://dx.doi.org/10.1186/BF03351769

Mel'nikov, M. E. (2005). Deposits of the Co-rich manganese crusts. Gelendzhik: GNTs Yuzhmorgeologiya [in Russian].

Petukhov, I. M., \& Batugina, I. M. (1999). Geodynamics of the Earth entrails. Moscow: Nedra communications Ltd [in Russian].

Petukhov, S. I., Aleksandrov, P. A., \& Andreev, S. I. (2010). Deformational model of hydrothermal sulphide ore fields for prediction of hydrothermal activity locations (for different areas of the Atlantic and Indian Oceans). Proceedings of the Joint International Conference on Minerals of the Ocean \& Deep-sea Minerals and Mining (pp. 70-72). St. Petersburg, Russia: VNIIOkeangeologia.

Pletnev, S. P., Mel'nikov, M. E., \& Punina, T. A. (2010). Cretaceous deposits of the guyots of the Magellan Seamounts, Pacific Ocean. In E. Yu. Baraboshkin, \& I. V. Blagoveschensky (Eds.), Cretaceous system in Russia and neighboring countries (pp. 283-286). Ulyanovsk: Ulyanovsk University, [in Russian].

Rashidov, V. A., Dolgal, A. S., \& Novikova, P. N. (2009). Geomagnetic investigation of the Vulkanolog and Kocebu Guyots (Magellan Seamounts, Pacific Ocean). Vestnik KRAUNTs: Nauki o Zemle, 1(13), 98-106.

Sedov, A. P., Matveenkov, V. V., Volokitina, L. P., Rashidov, V. A., Kazakevich, G. I., \& Lukyanov, S. V. (2005). Qualitative formation model of seamounts chains. Vestnik KRAUNTs: Nauki o Zemle, 5, 2-44. 
Utkin, V. P., Khanchuk, A. I., Mikhailik, E. V., \& Khershberg, L. B. (2004). The role of strike-slip faulting of oceanic crust in the formation of the Magellan Guyots (Pacific Ocean). Proceedings of the Academy of Science, Russia, 395(5), 646-650.

Volokhin, Y. G., Mel'nikov, M. E., \& Shkol'nik, E. L. (1995). Guyots of the western Pacific and their ore potential. Moscow: Nauka [in Russian].

\section{Copyrights}

Copyright for this article is retained by the authors, with first publication right granted to the journal.

This is an open-access article distributed under the terms and conditions of the Creative Commons Attribution license (http://creativecommons.org/licenses/by/3.0/). 